\title{
ANATOMIA DA MADEIRA DE MYRCEUGENIA MIERSIANA (GARDNER) D. LEGRAND ET KAUSEL (MYRTACEAE) ${ }^{1}$
}

\section{SIDINEI RODRIGUES DOS SANTOS² JOSÉ NEWTON CARDOSO MARCHIORI ${ }^{3}$}

\section{RESUMO}

A estrutura anatômica da madeira de Myrceugenia miersiana (Gardner) D. Legrand et Kausel é descrita, com base em material proveniente do Rio Grande do Sul, Brasil. Foram observados caracteres anatômicos pouco comuns para as Myrtaceae, tais como: placas de perfuração múltiplas, espessamentos espiralados nos vasos e pontoações raio-vasculares radialmente estendidas. Este conjunto de caracteres anatômicos é compartilhado por outras espécies nativas de Myrceugenia, motivo pelo qual é reconhecido como de valor diagnóstico para o gênero.

Palavras-chave: Myrceugenia miersiana, Anatomia da Madeira, Myrtaceae.

\section{ABSTRACT}

[Wood anatomy of Myrceugenia miersiana (Gardner) D. Legrand et Kausel (Myrtaceae)].

The wood anatomical structure of Myrceugenia miersiana (Gardner) D. Legrand et Kausel is described, based on samples from Rio Grande do Sul state, Brazil. The main wood anatomical features are unusual in family Myrtaceae: multiple perforation plates, spiral thickenings in vessel walls and radially extended vesselray pits (horizontal). This set of anatomical characters is shared by others Myrceugenia native species, being important, therefore, to the anatomical identification.

Key words: Myrceugenia miersiana, Wood Anatomy, Myrtaceae.

\section{INTRODUÇÃO}

O gênero Myrceugenia $\mathrm{O}$. Berg compreende cerca de 40 espécies, distribuídas desde a região subtropical brasileira até o Chile e as ilhas Juan Fernández (Landrum \& Kawasaki, 1997). Para o Brasil, são listadas 29 espécies e, destas, 14 ocorrem naturalmente em solo gaúcho (Sobral, 2003). A distribuição dos representantes brasileiros deste grupo, segundo Legrand \& Klein (1970), não ultrapassa o sul de Goiás.

A taxonomia de Myrceugenia, no que diz respeito ao seu correto posicionamento dentro das subtribos propostas por Berg (Sobral, 2003),

${ }^{1}$ Recebido para publicação em 22-1-2011 e aceito para publicação em 05-02-2011.

2 Biólogo, bolsista (CNPq-Brasil), doutorando do Programa de Pós-Graduação em Engenharia Florestal, Departamento de Ciências Florestais, Universidade Federal de Santa Maria. CEP 97105-900. Santa Maria, RS, Brasil.sthurt.bio@gmail.com

${ }^{3}$ Engenheiro Florestal, Dr. Bolsista de Produtividade em Pesquisa (CNPq - Brasil). Professor Titular do Departamento de Ciências Florestais, Universidade Federal de Santa Maria. Santa Maria, RS, Brasil. tem sido alvo de discussões, devido à presença simultânea de caracteres morfológicos associados com as três subtribos. Mesmo com as recentes alterações na circunscrição dos grupos infratribais, decorrentes de filogenias baseadas em moléculas de DNA (Lucas et al., 2005), ainda não foi possível esclarecer esta questão.

Tal situação recomenda a realização de estudos adicionais, com vistas à obtenção de novos elementos para auxiliar na resolução do problema. A anatomia da madeira, como alternativa, depende, todavia, da existência de uma base ampla de informações, de modo a possibilitar o estabelecimento de padrões estruturais para determinados grupos. A descrição anatômica da madeira de Myrceugenia miersiana, objetivo do presente estudo, visa a ampliar o conhecimento estrutural das Myrtaceae nativas, bem como contribuir ao esclarecimento de questões taxonômicas pendentes na família.

Arvoreta (4-6 m) de córtex rugoso, com ramos, flores, pecíolos e face abaxial das folhas cobertos de tricomas rufescentes, Myrceugenia 
miersiana apresenta folhas discolores e coriáceas, de forma oblonga ou lanceolada (50$110 \times 20-30 \mathrm{~mm}$ ), com nervuras salientes na face inferior. As flores, solitárias ou aos pares, são axilares e têm pedicelos de 3-4 mm de comprimento.

Conhecida vulgarmente por guamirim, a espécie distribui-se, no Brasil, de Minas Gerais ao Rio Grande do Sul (Landrum, 1981), habitando tanto a mata com Araucária, como a matinha nebular dos Campos de Cima da Serra (Sobral, 2003).

\section{REVISÃO DE LITERATURA}

Anatomicamente bem delimitado, o gênero Myrceugenia reúne características pouco comuns em Myrtaceae, tais como placas de perfuração escalariformes, vasos com espessamentos espiralados e pontoações raio-vasculares horizontalmente estendidas.

A presença de placas escalariformes e espessamentos espiralados, embora importante sob o ponto de vista taxonômico, não é restrita ao gênero em questão. Metcalfe \& Chalk (1972) relacionaram a presença de espessamentos espiralados para algumas espécies de Eugenia, bem como placas exclusivamente escalariformes em Myrtus. Segundo Schmid \& Baas (1984), placas escalariformes encontram-se, ainda, na estrutura anatômica de Luma, Myrteola, Ugni, e nos gêneros monotípicos Myrtastrum rufopunctatum, Neomyrtus pedunculata e Tepualia stipularis. Ugni candollei, por sua vez, também apresenta placas foraminadas. Espessamentos espiralados são observados em Acmena, Austromyrtus, Myrcia, Myrcianthes, Psidium, Xanthomyrtus e em Myrtus communis. Patel (1995), em estudo recente, estendeu a ocorrência de espessamentos espiralados e placas múltiplas às madeiras de Lophomyrtus e Neomyrtus.

No tocante às espécies brasileiras, a literatura refere placas de perfuração escalariformes para Siphoneugena densiflora (Paula et al., 2000), Gomidesia flagellaris e Gomidesia spectabilis (Andrade et al., 2010). Espessamentos espiralados, por sua vez, são referi- dos apenas para Campomanesia guazumifolia e Eugenia involucrata (Marchiori, 1984; 1998).

No Rio Grande do Sul, até o momento, foram investigadas apenas três espécies de Myrceugenia: Myrceugenia myrtoides (Marchiori \& Muñiz, 1987), Myrceugenia glaucescens (Marchiori \& Muñiz, 1988) e Myrceugenia euosma (Santos \& Marchiori, 2009). Em todas as três foram observados espessamentos espiralados; a ocorrência de placas escalariformes (não exclusivas), todavia, consta apenas para as duas últimas espécies. De acordo com Santos \& Marchiori (2009), das características listadas para Myrceugenia, a ocorrência de pontoações raio-vasculares horizontalmente estendidas é a de maior importância para a identificação, por ser a única restrita ao gênero em questão. Este caráter anatômico, no entanto, foi também encontrado na madeira de algumas espécies de Myrcia de outras regiões brasileiras (Barros \& Callado, 1997; Ovando et al, 2010).

Além de placas múltiplas, espessamentos espiralados e pontoações horizontalmente estendidas, são relacionados para Myrceugenia: vasos de diâmetro muito pequeno a pequeno, em número de 40 - 100 por $\mathrm{mm}^{2}$; parênquima predominantemente apotraqueal; raios heterogêneos, com mais de 10 fileiras marginais de células eretas; fibras com pontoações areoladas; e presença de séries cristalíferas no parênquima axial (Metcalfe \& Chalk, 1972).

\section{MATERIAL E MÉTODOS}

O material em estudo foi coletado em 15/ 10/2007, na Floresta Nacional de São Francisco de Paula, Rio Grande do Sul (Marchiori n. 1009), e consiste de um segmento de tronco e respectivo material botânico.

Do material lenhoso, foram extraídos três corpos de prova $(3 \times 3 \times 3 \mathrm{~cm})$ da parte mais externa do lenho, próxima ao câmbio, orientados para obtenção de cortes nos planos transversal, longitudinal radial e longitudinal tangencial. Um outro bloco foi também retirado, com vistas à maceração. 
No preparo das lâminas de cortes anatômicos, seguiu-se a técnica padrão no Laboratório de Anatomia da Madeira da Universidade Federal do Paraná: as amostras de madeira foram amolecidas por fervura em água e seccionadas em micrótomo de deslizamento, regulado para a obtenção de cortes com espessura nominal de $20 \mu \mathrm{m}$. Os cortes foram tingidos com acridina-vermelha, crisoidina e azulde-astra (Dujardin, 1964), desidratados em série alcoólica-ascendente $(30 \%, 50 \%, 70 \%, 95 \%$ e duas vezes em álcool absoluto) e diafanizados em xilol. Para o macerado, adotou-se o método de Jeffrey (Burger \& Richter, 1991) e coloração da pasta com safranina $1 \%$. A montagem das lâminas permanentes foi feita com Entellan.

A descrição microscópica da madeira baseou-se nas recomendações do IAWA Committee (1989). No caso da percentagem dos tecidos, foram realizadas 600 determinações ao acaso, com auxílio de contador de laboratório, conforme proposto por Marchiori (1980). A freqüência de poros $/ \mathrm{mm}^{2}$ foi obtida de forma indireta, a partir de um quadrado de área conhecida superposto a fotomicrografias de seção transversal da madeira.

As medições foram realizadas em microscópio Carl Zeiss, no Laboratório de Anatomia da Madeira da Universidade Federal de Santa Maria. Nas características quantitativas, os números entre parênteses equivalem aos valores mínimos e máximos observados; o valor que acompanha a média é o desvio padrão. As fotomicrografias foram tomadas em microscópio Olympus CX40, equipado com câmera digital Olympus Camedia c3000, no Laboratório de Anatomia da Madeira da Universidade Federal do Paraná, a quem os autores agradecem.

\section{DESCRIÇÃO ANATÔMICA}

Anéis de crescimento: distintos, delimitados por fina camada de fibras radialmente estreitas no lenho tardio e, por vezes, pelo alinhamento tangencial de poros no lenho inicial (Figura 1A,B). Porosidade difusa (Figura 1A).
Vasos: extremamente numerosos $(201 \pm 26$ (175 - 237) poros $/ \mathrm{mm}^{2}$ ), ocupando $23 \pm 5,1 \%$ do volume da madeira. Poros solitários e em frequiente contato lateral quando muito abundantes, poligonais, muito pequenos $(35 \pm 7,4$ $(20-45) \mu \mathrm{m})$, de paredes finas $(2,1 \pm 0,31(1,9$ $-2,5) \mu \mathrm{m})$ e sem padrão definido de organização (Figura 1A,B). Elementos vasculares de comprimento médio $(648 \pm 91,8(460-880 \mu \mathrm{m})$, com placas de perfuração geralmente oblíquas, simples, menos comumente múltiplas (reticuladas, escalariformes com $<10$ barras, ou mistas); apêndices em uma ou, mais comumente, em ambas as extremidades. Espessamentos espiralados grossos, embora tênues, presentes. Pontoações intervasculares alternas e opostas, circulares, ovais, até horizontalmente estendidas $(12,1 \pm 2,4(8,7-15) \mu \mathrm{m})$, com abertura em fenda inclusa, ornamentada (Figura 1F). Pontoações raio-vasculares com bordas reduzidas a aparentemente simples, grandes (14,5 \pm $6,2(6,2-25 \mu \mathrm{m})$ e horizontalmente estendidas (escalariformes), até circulares ou ovais quando menores, restritas às margens de raios (Figura 1D). Conteúdos, ausentes.

Parênquima axial: muito distinto das fibras em corte transversal, representando $26 \pm 4,5 \%$ do volume da madeira; em arranjo apotraqueal difuso e, principalmente, difuso-em-agregados, além de paratraqueal escasso (Figura 1A,B). Séries parenquimáticas com 4 - 8 células, medindo $592 \pm 93,2(370-740) \mu \mathrm{m}$ de altura (Figura 1F).

Raios: muito numerosos $(24 \pm 1,8(21-26)$ raios/mm), com 1 - 3 células de largura (Figura $1 \mathrm{E})$, ocupando $19 \pm 2,5 \%$ do volume da madeira. Raios multisseriados com $646 \pm 278,8$ (260 - 1300) $\mu \mathrm{m}$ e 10 - 27 (33) células de altura; heterogêneos, reúnem células procumbentes, na parte multisseriada, e 2-10 (13) fileiras marginais de células eretas e, menos comumente, quadradas e/ou procumbentes mais altas do que as do corpo central (Figura 1C). As margens unisseriadas são geralmente mais longas do que o corpo central (Figura 1E). Os unisseriados, 

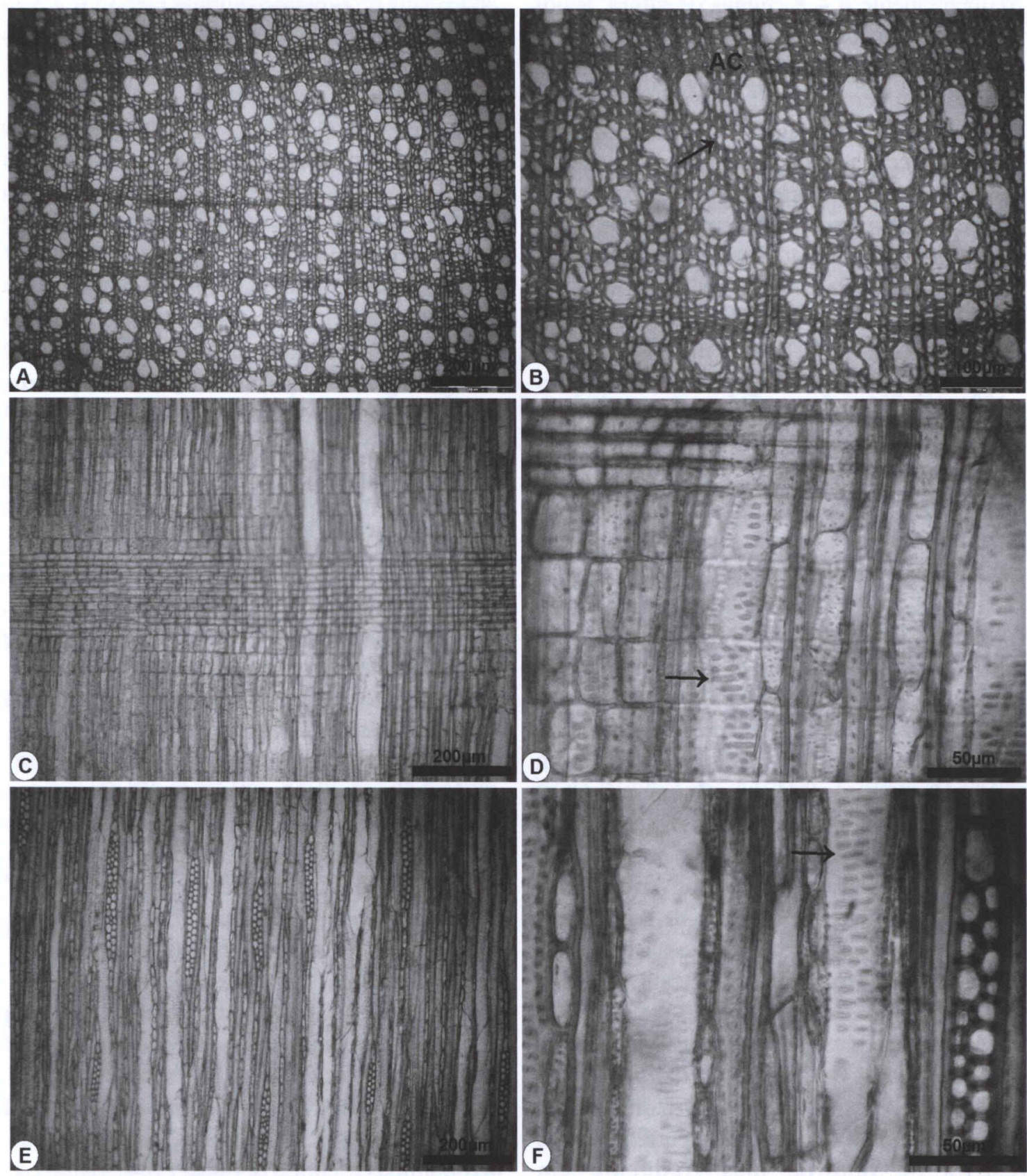

FIGURA 1 - Fotomicrografias da madeira de Myrceugenia miersiana. A - Seção transversal, mostrando porosidade difusa, poros solitários e em freqüente contato lateral. B - Mesma seção, em maior aumento, destacando poros de seção poligonal, parênquima difuso-em-agregados (seta), fibras de paredes finas a espessas e limite de anel de crescimento distinto (AC). C - Raio heterogêneo, composto por células procumbentes, na parte central, e predominantemente eretas, nas margens (seção longitudinal radial). D - Mesma seção, com destaque para pontoações raio-vasculares horizontalmente estendidas (seta). E - Aspecto geral dos raios, em seção longitudinal tangencial. F - Mesmo plano anatômico, mostrando pontoações intervasculares opostas, de forma oval até horizontais (seta), e raios uni e multisseriados. 
com $493 \pm 341(100-1420) \mu \mathrm{m}$ e $1-26$, mais frequentemente $4-8$ células de altura. Raios axialmente fusionados, pouco frequentes. Células radiais de paredes disjuntas, presentes. Inclusões minerais, células envolventes, células perfuradas e conteúdos, ausentes.

Fibras: com pontoações areoladas e aberturas cruzadas, presentes nas faces radiais e tangenciais da parede, representando $32 \pm 3,1 \%$ do volume da madeira; de comprimento médio $(1163 \pm 98,7(980-1400) \mu \mathrm{m})$, com 17,4 $\pm 2,5$ $(12,5-22,5) \mu \mathrm{m}$ de largura e paredes finas a espessas $(5,2 \pm 1,1(3,7-8,1) \mu \mathrm{m})$ (Figura 1B). Fibras septadas, fibras gelatinosas e espessamentos espiralados, ausentes. Traqueídeos vasicêntricos, presentes.

Outros caracteres: variantes cambiais, tubos laticíferos e taniníferos, canais intercelulares, máculas, células oleíferas ou mucilaginosas, estratificação e cristais, ausentes.

\section{ANÁLISE DA ESTRUTURA ANATÔMICA}

Os caracteres anatômicos de maior relevância na madeira de Myrceugenia miersiana incluem: poros solitários muito pequenos; elementos vasculares de comprimento médio, com pontoações ornamentadas; parênquima apotraqueal difuso-em-agregados; raios heterogêneos, estreitos; fibras de comprimento médio, com pontoações areoladas; e traqueídeos vasicêntricos. Cabe salientar que este conjunto de características é comum à maioria das Myrtaceae, de acordo com Record \& Hess (1949), Metcalfe \& Chalk (1972) e Vliet \& Baas (1984).

A presença de espessamentos espiralados em vasos, de placas de perfuração múltiplas e de pontoações raios-vasculares horizontalmente estendidas, por outro lado, tem ocorrência mais restrita na família, mas freqüente em Myrceugenia. Como já salientado, espessamentos espiralados e pontoações raio-vasculares horizontais são comuns a todas as espécies nativas deste gênero, referidas na literatura; placas múltiplas, no entanto, não ocorrem em todas as espécies, caso de Myrceugenia myrtoides (Marchiori, 1987).
Schmid \& Baas (1984), ao investigarem a ocorrência de espessamentos espiralados e placas de perfuração escalariformes em Myrtaceae, também observaram a combinação destas duas características no gênero Myrceugenia, salientando, todavia, que as mesmas nem sempre estão presentes e podem faltar, inclusive, em diferentes indivíduos de uma mesma espécie. Santos \& Marchiori (2009), por sua vez, agregam a presença de pontoações raio-vasculares horizontalmente estendidas, em consonância com os resultados do presente estudo.

Recentemente, demonstrou-se que espécies de alguns gêneros, na Austrália, também podem apresentar a referida combinação de características anatômicas (Patel, 1995). Este aspecto, apesar de limitar a consistência do caráter para a diagnose do gênero, não impede o seu uso, pelo menos entre os representantes brasileiros da família, principalmente devido ao fato de que, fora do grupo taxonômico em questão, nenhuma outra espécie nativa conta com a ocorrência concomitante de ambos os caracteres. Considerados isoladamente, os mesmos tem valor taxonômico mais limitado, uma vez que também ocorrem em outros gêneros de Myrtaceae.

A presença deste conjunto de caracteres anatômicos e a grande homogeneidade estrutural favorecem a identificação do gênero, ao mesmo tempo que dificultam ou impossibilitam a separação de suas espécies. Das características qualitativas referidas na literatura para espécies nativas de Myrceugenia, encontra-se discrepância apenas no tocante à presença ou não de perfurações escalariformes. Vale lembrar que este detalhe anatômico pode ser ocasional, inclusive entre indivíduos de uma mesma espécie, o que reduz sua consistência para fins taxonômicos (Schmid \& Baas, 1984). Santos \& Marchiori (2009), em estudo de Myrceugenia euosma, encontraram placas múltiplas escassas até muito freqüentes nas amostras investigadas, confirmando a variabilidade intrínseca do caráter no gênero.

Metcalfe \& Chalk (1972) citam a presença de séries cristalíferas no parênquima axial de 
algumas espécies de Myrceugenia, contrariamente ao observado no presente estudo, bem como ao referido por Marchiori \& Muñiz (1987; 1988) e Santos \& Marchiori (2009).

As características quantitativas também pouco diferem entre as espécies nativas do gênero, incluindo a espécie em estudo. Pequenas discrepâncias foram observadas no tocante à freqüência de poros, comprimento de elementos vasculares, altura das séries de parênquima axial, bem como na largura e altura de raios, aspectos que podem ser úteis na separação das espécies.

\section{REFERÊNCIAS BIBLIOGRÁFICAS}

ANDRADE, I.M.; LONGUI, E.L.; SANTINI JUNIOR, L.; SOBRAL, E.S.; AGUIAR, O.T.; FLORSHEIM, S.M.B.; LIMA, I.L. Anatomia comparada do lenho de quatro espécies de Gomidesia spp. Berg (Myrtaceae) do Parque Estadual Carlos Botelho - SP. $4^{\circ}$ Seminário de Iniciação Científica do Instituto Florestal, 2010.

BURGER, L.M.; RICHTER, H.G. Anatomia da Madeira. São Paulo: Ed. Nobel, 1991. 154 p.

BARROS, C.F.; CALLADO, C.H. Madeiras da mata atlântica. Anatomia do lenho de espécies ocorrentes nos remanescentes florestais do estado do Rio de Janeiro, Brasil. Rio de Janeiro: Instituto de Pesquisas Jardim Botânico do Rio de Janeiro. 1997. v. 1.86 p.

DUJARDIN, E.P. Eine neue Holz-Zellulosenfaerbung. Mikrokosmos, n. 53, p.94, 1964.

IAWA COMMITTEE. IAWA list of microscopic features for hardwood identification. IAWA Bulletin., v.10, n. 3, p.218-359, 1989.

LANDRUM, L.R. A monograph of the genus Myrceugenia. Flora Neotropica. n. 29, p. 1-137, 1981.

LANDRUM, L.R.; KAWASAKI, M.L. The genera of Myrtaceae in Brasil: an illustrated synoptic treatment and identification keys. Brittonia, n. 49, p. 508-536, 1997.

LEGRAND, D.; KLEIN, R.M. Mirtáceas. Flora Ilustrada Catarinense. Itajaí: Herbário Barbosa Rodrigues, 1970. p. 33-453.
LUCAS, E.J.; BELSHAM, S.R.; NIC LUGHADHA, E.M.; ORLOVICH, D.A. SAKURAGUI, C.M.; CHASE, M.W.; WILSON, P.G. Phylogenetic patterns in the fleshy-fruited Myrtaceae preliminary molecular evidence. Plant Systematics and Evolution, v. 251, p. 35-51, 2005.

MARCHIORI, J.N.C. Estudo anatômico do xilema secundário de algumas espécies dos gêneros Acacia e Mimosa, nativas no Estado do Rio Grande do Sul. 186f. Dissertação (Mestrado em Engenharia Florestal) - Universidade Federal do Paraná, Curitiba, 1980.

MARCHIORI, J.N.C. Anatomia da madeira de Eugenia involucrata DC. (Myrtaceae). Ciência e Natura, Santa Maria, v. 6, p. 127-136, 1984.

MARCHIORI, J.N.C. Estudo anatômico da madeira de sete-capotes, Campomanesia guazumifolia (Camb.) Berg. (Myrtaceae). Ciência Rural, Santa Maria, v. 28, n. 1, p. 47-51, 1998.

MARCHIORI, J.N.C.; MUÑIZ, G.I.B. Anatomia descritiva da madeira de Myrcengenia myrtoides Berg. Ciência e Natura, Santa Maria, v. 9, p. 113-120, 1987.

MARCHIORI, J.N.C.; MUÑIZ, G.I.B. Estudo anatômico da madeira de Myrceugenia glaucescens (Camb.) Legr. et Kaus. Ciência e Natura, Santa Maria, v. 10, p. 105-113, 1988.

METCALFE, C.R.; CHALK, L. Anatomy of the Dicotyledons. Oxford: Clarendon Press, 1972. 1500p.

OVANDO, P.C.; LONGUI, E.L.; ROMEIRO, D.; SANTINI JUNIOR, L.; AGUIAR, O.T.; FLORSHEIM, S.M.B.; LIMA, I.L. Anatomia do lenho de Myrcia albotomentosa DC. e Myrcia multiflora (Lam.) DC. (Myrtaceae). $4^{\circ}$ Seminário de Iniciação Científica do Instituto Florestal, 2010.

PATEL, R.N. Wood anatomy of the dicotyledons indigenous to New Zealand. 25 Myrtaceae subfam. Myrtoideae (part 1). New Zealand Journal of Botany, v. 33, p. 541-555, 1995.

PAULA, J.E de; JUNIOR, F.G.S.; SILVA, A.P.P. Caracterização anatômica de madeiras nativas de matas ciliares do centro-oeste brasileiro. Scientia Forestalis, v. 58, p. 73-89, 2000. 
RECORD, S.J.; HESS, R. W. Timbers of the New World. New Haven: Yale University Press, 1949. 640p.

SANTOS S.R.; MARCHIORI, J.N.C. Anatomia do xilema secundário de Myrceugenia euosma (O. Berg) D. Legrand. Balduinia, n. 16, p. 24-29, 2009.

SCHMID, R.; BAAS, P. The occurrence of scalariform perforation plates and helical thickenings in wood of Myrtaceae. IAWA Bulletin, v. 5, n. 3, p. 197-215, 1984.

SOBRAL, M. A família Myrtaceae no Rio Grande do Sul. São Leopoldo: Editora Unisinos, 2003. p. 64-65.

VLIET, G.J.C. van; BAAS, P. Wood anatomy and classification of the Myrtales. Annals of the Missouri Botanical Garden, n. 71, p. 783-800, 1984. 